\title{
Treatment Adherence among Tuberculosis and Human Immuno Deficiency Virus Coinfected Patients in Ginnir Referral Hospital
}

\author{
Ahmed Yasin Mohammed*, Muhammedawel Kaso Adem \\ Department of Public Health, College of Medicine and Health Science, Madawalabu University, Bale Goba \\ *Corresponding author: ahmedyassinmoha@yahoo.com
}

Received October 13, 2014; Revised November 01, 2014; Accepted November 30, 2014

\begin{abstract}
Tuberculosis is a major public health problem in Ethiopia, and a high number of TB patients are coinfected with HIV. There is a need for more knowledge about factors influencing treatment adherence in co-infected patients on concomitant treatment. The objective of this study is to assess treatment adherence among TB/HIV co infected patients in Ginnir referral hospital from March - April 2013. Institution based cross sectional study design was used to collect, analyze and summarize data from TB/HIV co-infected patients. The data was sorted manually and scientific calculator was used to compile and express in table and graphs. Descriptive statistics like frequencies, mean and median were used to analyze the data. Prior to data collection, permission request was obtained from Madawalabu University, Goba campus and it was submitted to Ginnir referral hospital's medical director. Respondents were told about the objective of this study, reassured for confidentiality and asked for consent. The results shown among the 53 TB/HIV co- infected patients, 11(20.7\%) had missed taking both ARV and anti TB drugs at least once. Of these, 4 (36.4\%) had missed the ARV treatment while remaining 7(63.6\%) of them missed the anti TB medication. The result showed that, the main reason for missing the drugs was forgetting taking medication $6(54.6 \%)$. It can be concluded that the level of non adherence is relatively high and the main reason behind was forgetting distance from health institution and income related problems. Intervention s to reduce it need to be instituted such as adherence educations should have to be given for the patients to take the treatment by the recommended schedule and also family members and supporters should have to be told to remind and follow them carefully. On the other hand bringing the health service nearby might alleviate the problem of distance. In order to deal with the income related problems, Ginnir referral hospital should have to work in collaboration with NGOs and other fund raising institutions.
\end{abstract}

Keywords: Treatment adherence, tuberculosis and human immuno deficiency virus co-infected patients

Cite This Article: Ahmed Yasin Mohammed, and Muhammedawel Kaso Adem, “Treatment Adherence among Tuberculosis and Human Immuno Deficiency Virus Coinfected Patients in Ginnir Referral Hospital.” American Journal of Public Health Research, vol. 2, no. 6 (2014): 239-243. doi: 10.12691/ajphr-2-6-4.

\section{Introduction}

Worldwide approximately one third of all acquired immune deficiency syndrome (AIDS) related deaths are associated with tuberculosis (TB) and TB is the primary cause of death for $10-15 \%$ of patients with human immunodeficiency virus (HIV) infection. Untreated TB can accelerate the progression of HIV infection. The epidemics of TB embedded in epidemic of HIV infection represent the greatest health risk to general public and the health care profession [1].

HIV epidemic has led to an increase in the incidence of tuberculosis globally, particularly in sub-Saharan Africa [1]. According to the 2007 report of World Health Organizations (WHO), one third of the world's population is estimated to be infected with Tubercle bacilli and is at risk of developing the active disease [2]. In sub-Saharan Africa, as high as two third of tuberculosis patients are
HIV/AIDS co-infected and tuberculosis is the most common cause of death among HIV/AIDS patients worldwide [3]. TB/HIV co-infection also leads to difficulties in both the diagnosis and treatment. And constitute an immense burden on healthcare systems of heavily infected countries like Ethiopia [4].

According to the 2008 report of WHO Ethiopia ranks seventh among the world's 22 countries with a high TB burden [5]. The federal ministry of health (FMOH) hospital statistics data has shown that TB is the leading cause of morbidity, the third cause of hospital admission (after deliveries and malaria) and the second cause of death in Ethiopia after malaria [6].

Since TB is a major public health problem in Ethiopia, and a high number of TB patients are co-infected with $\mathrm{HIV}$, there is a need for more knowledge about factors influencing treatment adherence in co-infected patients on concomitant treatment [7]. Adherence is a concept that allows for a comprehensive assessment of factors related 
to medication intake such as characteristics of the regimen; attitudes of the providers; socio-economic, cultural and environmental factors [8]. Low adherence to TB treatment can lead to an increased risk of drug resistance, relapse, death, and may prolong infectiousness [9]. Thus, the overall purpose of this study is to investigate the treatment adherence among patients co-infected with TB and HIV in Ginnir referral hospital.

The major reason to conduct this research is, TB threatens HIV-infected patients and is rapidly fatal when there is treatment non adherence [4]. Low or non adherence to TB treatment can lead to an increased risk of drug resistance, relapse, and death and may prolong infectiousness [10]. Evidence shows that ART treatment can have a significant impact on the HIV and TB related morbidity and mortality in co-infected patients; but concomitant treatment is complicated by factors such as overlapping drug toxicities, drug-drug interactions and possible paradoxical reactions [5]. Concomitant treatment also leads to a higher pill burden. There is an association between poor adherence and the pill burden associated with a regimen, the regimen's complexity, and the extent to which the regimen impacts on the patient's daily life. Co-infected patients on concomitant treatment may thus be at risk for decreased adherence to either or both treatments [6].

The problem of non-adherence to treatment, i.e. deviation from a prescribed treatment regimen by for example irregular medication intake or premature termination of treatment, is known to all medical disciplines; between $30 \%$ and $60 \%$ of medicines are not taken as prescribed. Poor treatment adherence is associated with severe morbidity and mortality, and it contributes significantly to the overall cost of healthcare [8]. The difficulty experienced by patients following a particular treatment regimen has raised awareness of adherence as a complex behavioral issue, influenced by many factors, including age, gender, marital status and educational status. WHO has attempted to classify factors that influence adherence to TB treatment based on a cursory review of key papers [11].

Problems manifesting specifically at health facilities included long waiting times, queues, lack of privacy, inconvenient appointment times [12] and the poor upkeep of clinics [13]. Many studies reported that patients experienced difficulty in accessing treatment at health care facilities because of inconvenient opening hours and provider absenteeism [1]. Poor TB medication availability at health care facilities was highlighted by patients [10] and providers [7].

Thus, an enhanced, refocused research agenda is critical to overcome the problems with treatment adherence among TB/HIV co infection.

The significance of this study is to contribute to the effort against treatment non adherence among TB/HIV coinfected patients and problems related to treatment adherence. The study findings will help the health service organization (Ginnir referral hospital) and Ginnir woreda health bureau to design strategies to solve health problems related to TB/HIV co infection and treatment adherence. And also it can help the Anti TB and ART clinic staffs to put their own effort to struggle against non adherence and awareness creation.
And also it could help in exploring patient's views about TB treatment and ART adherence among TB/HIV co infected patients. On the other hand this study can be used by a researcher who wish to do further investigation on this topic and it can help in identifying the health professionals role on a favor of anti TB and ARV treatment. Furthermore, the results will help in the major efforts targeting at resolving the problem with treatment adherence in TB/HIV co infected patient.

\section{Methodology}

\subsection{Study Area and Period}

The study was conducted in Ginnir Referral Hospital, Ginnir town, Bale Zone, Oromia Region, south east Ethiopia. Ginnir is found in South East at a distance of $570 \mathrm{~km}$ from Addis Ababa and 140km from zonal town Robe. The total populations of the district were 165,693, among them 84,711 are males. Ginnir town is located about 1750- 1900 meters above sea levels and its climatic condition is 'Weyna dega'. The District has 27 Kebele's, among this four of them are urban and the total population of the urban accounts 25,925, and the rest are rural and their total population accounts 139,769. The District has one zonal Hospital, namely Ginnir referral Hospital, 6 functional Health Centers, 21 Health Posts and 12 Private Clinics (Ginnir woreda administrative bureau). The study period will be from March 2012- April 2013.

\subsection{Study Design}

An institution based cross sectional study was conducted.

\subsection{Source Population and Study Population}

The source population was all patients who were infected by TB and HIV receiving treatment at Ginnir Referral Hospital.

\subsection{Sampling Procedure and Method}

\subsubsection{Sampling Method}

The study units that happen to be available at the time of data collection were selected to assess treatment adherence among TB/HIV co infected patients.

\subsubsection{Sampling Procedure}

First revision of the registry document was undertaken in the ART and anti TB clinics to obtain the list of existing co- infected patients. Then it was identified that there were small number (53) of TB/HIV co- infected patients. Finally, we took all the patients to participate in the study.

\subsection{Method of Data Collection}

Data was collected by using structured questionnaire and interview method in the ART and anti TB clinics by the research group members starting from March 23-April 03 among TB and HIV co-infected patient who are taking treatment at Ginnir referral hospital. 


\subsection{Data Quality Control}

The questionnaire was translated to the Afan Oromo and was checked for completeness to insure the quality of the information.

\subsection{Data Processing and Analysis}

Data was processed and analyzed using SPSS version 16. Then, summarized and described in tables. The frequency and cross tabulation of data with different variables was performed.

\subsection{Ethical Consideration}

Prior to data collection ethical clearance was taken from ethical committee of Madawalabu University, Goba campus collage of medicine and health science and it was submitted to Ginnir Referral Hospital's medical director. Respondents were told about the objective of this study, reassured for confidentiality and asked for consent.

\section{Result}

\subsection{Socio Demographic Characteristics}

Table 1. Socio demographic characteristics of TB/HIV co- infected patients in Ginnir referral hospital, Ginnir, Bale Ethiopia, 2005EC

\begin{tabular}{|c|c|c|c|}
\hline \multicolumn{2}{|l|}{ Characters } & Frequency & Percentage \\
\hline \multirow{5}{*}{ Age } & $<14$ & 4 & 7.55 \\
\hline & $15-24$ & 9 & 17 \\
\hline & $25-34$ & 22 & 41.5 \\
\hline & $35-44$ & 12 & 22.64 \\
\hline & $>45$ & 6 & 11.32 \\
\hline \multirow{2}{*}{ Sex } & Male & 25 & 47.2 \\
\hline & Female & 28 & 53.8 \\
\hline \multirow{3}{*}{ Religion } & Muslim & 32 & 60.4 \\
\hline & Orthodox & 18 & 33.9 \\
\hline & Protestant & 3 & 5.7 \\
\hline \multirow{4}{*}{ Ethnicity } & Oromo & 29 & 54.7 \\
\hline & Amhara & 12 & 22.6 \\
\hline & Somali & 11 & 20.8 \\
\hline & Other* & 1 & 1.9 \\
\hline \multirow{2}{*}{ Residence } & Urban & 34 & 64.2 \\
\hline & Rural & 19 & 35.8 \\
\hline \multirow{4}{*}{ Marital status } & Single & 18 & 34 \\
\hline & Married & 27 & 50.9 \\
\hline & Divorced & 2 & 3.8 \\
\hline & Widowed & 6 & 11.3 \\
\hline \multirow{3}{*}{ Family size } & $<2$ & 6 & 11.3 \\
\hline & $3-5$ & 26 & 49.1 \\
\hline & $>6$ & 21 & 39.6 \\
\hline \multirow{5}{*}{ Education } & Illiterate & 19 & 35.9 \\
\hline & Read and write & 6 & 11.3 \\
\hline & Primary & 19 & 35.9 \\
\hline & Secondary & 7 & 13.2 \\
\hline & $>12$ & 2 & 3.8 \\
\hline \multirow{9}{*}{ Occupation } & Farmer & 9 & 35.8 \\
\hline & House wife & 12 & 24.5 \\
\hline & Government employee & 3 & 5.7 \\
\hline & NGO & 3 & 5.7 \\
\hline & Student & 6 & 11.3 \\
\hline & Non employee & 3 & 5.7 \\
\hline & House maid & 3 & 5.7 \\
\hline & Daily labor & 10 & 18.9 \\
\hline & Other** & 4 & 7.6 \\
\hline
\end{tabular}

Other*- Wolayita,

Other**- Merchant, commercial sex worker.
There were 124 patients on anti TB and 1013 patients on ARV treatment. From these patients, 53 were coinfected by TB and HIV and were following both ART and anti TB treatment in Ginnir referral hospital. Among these TB/HIV co infected patients, 28(53.8\%) were female and 25(47.2\%) were male with male to female ratio 5:6. Of these, the majority $22(41.5 \%)$ were in the age group of 25-34 years with mean age of 31 (SD. \pm 16.93 ). The dominant religion and ethnicity of our study population were Muslim 32 (60.4\%) and Oromo 29 (54.7\%) respectively. The majority 34(64.2\%) were from urban and nearly more than half of the patients can read and write, and 19(35.8\%) attended primary education. Twenty seven (50.94\%) of our study population were married, 18(33.96\%) were single and the remaining were divorced and widowed. Among those patients, house wives account $13(24.5 \%)$ of the total occupations (Table 1 ).

Most 30(52.8\%) of our study population has an income in the range of $300-1000$ birr and $8(15 \%)$ has $<300$ birr per month. Forty one (77.4\%) has the access to radio and television and 30(56.6\%) has been using phone. When we detect their living condition, 48 (90.6\%) lives with their family of which $30(56.6 \%)$ were supported by their family members where as $15(28.3 \%$ ) by their spouse (Table 2).

Table 2. Socio- economic and information access of TB/HIV coinfected patients in Ginnir referral hospital, Ginnir, Bale Ethiopia, 2005EC

\begin{tabular}{|c|c|c|c|}
\hline \multicolumn{2}{|l|}{ Variable } & Frequency & Percentage \\
\hline \multirow{3}{*}{ Income per month } & $<300$ & 8 & 15.1 \\
\hline & $300-1000$ & 30 & 56.6 \\
\hline & $>1000$ & 11 & 20.8 \\
\hline \multirow{2}{*}{ Radio } & Yes & 41 & 77.4 \\
\hline & No & 12 & 22.6 \\
\hline \multirow{2}{*}{ Television } & Yes & 17 & 32.1 \\
\hline & No & 36 & 67.9 \\
\hline \multirow{2}{*}{ Phone } & Yes & 3o & 56.6 \\
\hline & No & 23 & 43.4 \\
\hline \multirow{2}{*}{ Type of house } & Grass & 11 & 20.7 \\
\hline & Steel & 42 & 79.3 \\
\hline \multirow{2}{*}{ Living situation } & With family & 49 & 92.5 \\
\hline & In prison & 4 & 7.6 \\
\hline \multirow{4}{*}{ Relation with supporter } & Family member & 33 & 62.3 \\
\hline & Spouse & 15 & 28.3 \\
\hline & No supporter & 1 & 1.9 \\
\hline & Non family & 4 & 7.6 \\
\hline
\end{tabular}

\subsection{Treatment Adherence among TB and HIV Co-infected Patients}

Among the total 53 TB/HIV co-infected patients, 44(83\%) were diagnosed for pulmonary $\mathrm{TB}$ and the remaining were extra pulmonary TB positive. Among the total patients in the study, 44(83\%) have the awareness of how TB can be transmitted and 42(95.5\%) take measures to prevent its transmission to their family members. Forty (40\%) participants had the knowledge on the consequence of missing drug and 18 (33.9\%) did not feel ashamed towards being on treatment. In this study we have seen that, the participants were facing challenges. For example $13(24.5 \%)$ transportation and $16(30.2 \%)$ had faced lack of support from others (Table 3). 
Table 3. Treatment adherence among TB/HIV co- infected patients in Ginnir referral hospital, Ginnir, Bale Ethiopia, 2005EC

\begin{tabular}{|c|c|c|c|}
\hline \multicolumn{2}{|c|}{ Variable } & Frequency & Percentage \\
\hline \multirow{2}{*}{ Type of TB } & PTB & 44 & 83.0 \\
\hline & ETB & 9 & 16.9 \\
\hline \multirow{2}{*}{$\begin{array}{l}\text { Knowledge on } \\
\text { TB transmission }\end{array}$} & Yes & 44 & 83.0 \\
\hline & No & 9 & 16.9 \\
\hline \multirow{2}{*}{$\begin{array}{l}\text { Measure to } \\
\text { prevent } \\
\text { transmission }\end{array}$} & Yes & 42 & 79.24 \\
\hline & No & 2 & 3.7 \\
\hline \multirow{2}{*}{$\begin{array}{l}\text { Knowledge on } \\
\text { the consequence } \\
\text { of missing drug }\end{array}$} & Yes & 40 & 75.5 \\
\hline & No & 13 & 24.5 \\
\hline \multirow{2}{*}{$\begin{array}{l}\text { Feeling towards } \\
\text { being on } \\
\text { treatment }\end{array}$} & Feel ashamed & 18 & 33.9 \\
\hline & Don't feel ashamed & 35 & 66.0 \\
\hline \multirow{4}{*}{ Challenge } & Transport & 13 & 24.5 \\
\hline & Physical weakness & 7 & 13.2 \\
\hline & Lack of support & 16 & 30.2 \\
\hline & Stigma & 6 & 11.3 \\
\hline \multirow{2}{*}{ Side effect } & Yes & 41 & 77.4 \\
\hline & No & 12 & 22.6 \\
\hline \multirow{6}{*}{ Which side effect } & Body weakness & 19 & 35.8 \\
\hline & Headache & 7 & 13.2 \\
\hline & Night mare & 3 & 5.7 \\
\hline & Rash & 9 & 16.9 \\
\hline & Vomiting & 7 & 13.2 \\
\hline & Other* & 5 & 9.4 \\
\hline \multirow{2}{*}{$\begin{array}{l}\text { Relation with } \\
\text { health care } \\
\text { provider }\end{array}$} & Encouraging & 29 & 54.7 \\
\hline & Respectful & 24 & 45.3 \\
\hline \multirow{2}{*}{ Addiction } & Yes & 27 & 50.9 \\
\hline & No & 26 & 49.0 \\
\hline \multirow{3}{*}{ Which addiction } & Cigarette & 11 & 20.8 \\
\hline & Alcohol & 11 & 20.8 \\
\hline & Chat & 19 & 35.9 \\
\hline
\end{tabular}

Other*- Urine discoloration, burning epigastric pain.

On the other hand 44(83\%) also had informed about potential side effects of the drugs and adherence education had been given by the health professionals. Drug side effects were seen on $41(77.4 \%)$ of the patients. Of these 19(46.3\%) of them had complained body weakness, 9(16.9) of them had body rash, 7(13.2\%) headache and the remaining had experienced vomiting and night mare. From the total study population, 27(50.9\%) had addiction. Of these, cigarette and alcohol addiction account 17(32\%) while 19(35.8\%) for chat (Table 4).

Forty four (83.1\%) patients had gotten adherence education. Of the total patients on treatment, 11(20.7\%) had missed taking the drug at least once. Among the patients who had missed taking the medication 4 (36.4\%) of them had missed the ARV treatment while remaining 7(63.6\%) of them missed the anti TB medication. The result showed that, the main reason for missing the drugs was $6(54.6 \%)$ forgetting. Five (45.5\%) of them didn't take any measure while $6(54.6 \%)$ had taken their pill immediately as they had remembered.

Since $46(86.8 \%)$ of our participants were under DOT, they should have to come to the hospital daily so as to get the service. As a result of this, 10(18.9\%) should have to walk for greater than 2 hours, 16(30.2\%) for more than 1 hour and 19(35.9\%) for 30 minutes.

Table 4. Treatment adherence among TB/HIV co- infected patients in Ginnir referral hospital, Ginnir, Bale Ethiopia, 2005EC

\begin{tabular}{|l|l|l|l|}
\hline \multicolumn{2}{|c|}{ Variables } & Frequency & Percentage \\
\hline \multirow{2}{*}{$\begin{array}{l}\text { Adherence } \\
\text { education recently }\end{array}$} & Yes & 44 & 83.0 \\
\cline { 2 - 4 } & No & 9 & 16.9 \\
\hline $\begin{array}{l}\text { Take drug under the } \\
\text { observation of } \\
\text { health professional }\end{array}$ & Yes & 46 & 86.8 \\
\cline { 2 - 4 } & No & 7 & 13.2 \\
\hline
\end{tabular}

\begin{tabular}{|c|c|c|c|}
\hline \multirow{6}{*}{ Distance } & No & & \\
\hline & $\begin{array}{l}\text { Very far (> } 2 \\
\text { hour walk) }\end{array}$ & 10 & 18.9 \\
\hline & $\begin{array}{l}\text { Far(>1 hour } \\
\text { walk) }\end{array}$ & 16 & 30.2 \\
\hline & $\begin{array}{l}\text { Moderate (> } 30 \\
\text { min walk) }\end{array}$ & 19 & 35.9 \\
\hline & $\begin{array}{l}\text { Nearby }(<30 \\
\text { min walk) }\end{array}$ & 6 & 11.3 \\
\hline & Very near & 2 & 3.7 \\
\hline \multirow{2}{*}{$\begin{array}{l}\text { Missed taking the } \\
\text { ARV and anti TB } \\
\text { drug }\end{array}$} & Yes & 11 & 20.7 \\
\hline & No & 42 & 79.3 \\
\hline \multirow[t]{4}{*}{ Reason for missing } & Forgetting & 6 & 11.3 \\
\hline & Feel better & 3 & 5.7 \\
\hline & Feel worse & 1 & 1.9 \\
\hline & Getting bored & 1 & 1.9 \\
\hline \multirow{2}{*}{$\begin{array}{l}\text { Measure taken to } \\
\text { compensate }\end{array}$} & $\begin{array}{l}\text { No measure } \\
\text { taken }\end{array}$ & 6 & 11.6 \\
\hline & $\begin{array}{l}\text { Take } \\
\text { immediately }\end{array}$ & 5 & 9.4 \\
\hline
\end{tabular}

\section{Discussion}

Patients with HIV and TB are likely to face more challenges because they have to get HIV care in addition to the TB care. This may lead to poorer adherence among these patients and yet because of their immune suppression, are likely to get more severe forms of TB [12]. The purpose of this study is to assess treatment adherence among TB/HIV co infected patients in Ginnir referral hospital.

Similar study which was conducted in Mbrara hospital in Uganda showed that about $75 \%$ of individuals who were included in the study had adhered to anti TB treatment [17]. The possible explanation for this can be, being on DOT helped the patients to get the service and information frequently. This can increase their awareness towards the consequence of non adherence. On the other hand provision of treatment service without any payment encourages the patients to take the medication appropriately. Likewise, preparation of anti TB drugs in combination and its frequency (which is taken once per a day decreases pill burden) enhanced adherence. Since half of the participants were married, that they help each other economically, psychologically and morally to take their medication without interruption.

On the other hand this study shows $92.4 \%$ of patients adhere to ARV treatment. This result is almost similar to that of the study done in Tercha district hospital in Ethiopia which shows $95.8 \%$ of individuals involved in the study adhere to ARV treatment [19]. Similarly a cross- 
sectional study which was done in kenya also had the same result [14]. The main reason behind might be, most of our study population had gotten adherence education by the health care providers at ART clinic that helped them to get through the treatment correctly. The educational status of our study population has helped them to adhere to their ARV treatments. This might be due to, those who are educated can easily understand the severity and complication of not taking treatment appropriately and apply what they have been thought by the health care provider. In addition to this, living nearby to the hospital increased their adherence to the ARV medication. And they can get advice from the health care provider at any time they need.

Since the interaction between the health care provider and patients is crucial to treatment adherence, non adherence was affected by the health care providers in the study which was done in Delhi, India [20]. In this particular study, all of the study population mentioned their relationship with health care provider as encouraging and respectful. Poor follow up and mal treatment such as scolding a patient for missing appointment were not mentioned. This might be due to, the interview was undertaken in the presence of the health care providers in the ART and anti TB clinics that the participants might be afraid to mention their complain.

Since the interaction between health care providers and the patients is crucial to treatment adherence, there was no significant association between attitude of health care providers and non-adherence in the study which was done in Delhi, India [20]. Similarly, all of our study participants mentioned their relationship with health care providers as encouraging and respectful. Poor follow up and maltreatment by health care provider such as scolding a patient for missing appointment were not mentioned. This might be due to the interview was undertaken in the presence of the health care providers at ART and anti TB clinics that the participants might be afraid to mention their complain.

Even though most of the study population had adhered to both treatments in this study, there are also patients who were non adherent to the treatments. This is most likely due to low income which cannot cover their transportation cost and family expenditure and forgetting taking medication in the recommended dose and time. Other than this, long distance from the hospital affects patient's motivation or their will to collect the medication from the hospital by the time they need to refill. This finally leads to non adherence for both anti TB and ARV treatments.

\section{Conclusion}

The level of non adherence is relatively high. This might lead to drug resistance and treatment failure which finally results in further morbidity and mortality. Since the main reason for non-adherence were forgetting, distance and income related problem. Interventions to reduce it needed to be instituted. Adherence educations should have to be given for the patients to take the treatment by the recommended schedule and also family members and supporters should have to be told to remind and follow them carefully.
In order to deal with the above problem, Ginnir referral hospital should have to work in collaboration with NGOs and other fund raising institution to solve the income related problems. And also education campaigns and counseling by healthcare providers are required to improve awareness among TB/HIV co- infected patients.

Likewise Ginnir woreda health bureau also have to play the major role to solve their problems by bringing the health service nearby or creating suitable condition by which ARV and anti TB medications are started at remote area health centers.

\section{References}

[1] Swaminath S, Padmapaiyadarsini C and Narendran G (2011). HIV-Associated Tuberculosis. J Manag Care Pharm, 17(3), 21323.

[2] World Health Organization (2007). Global Tuberculosis Control: Surveillance, Planning, Financing. WHO report.

[3] Afework K, Mengistu G, Ayele B (2007).Co-infection and clinical manifestation of TB in HIV infected and uninfected adults at teaching hospital. J Microbial Immunol Infect. 25, 135-143.

[4] Demissie M, Lindtjon B, Tegbaru B (2000).Human Immunodeficiency virus (HIV) infection in tuberculosis patients. $J$ Health Dev, 60, 564-674.

[5] Anthony Harries Stephen Graham Dermot Maher (2004). Department of child and adolescent health and development, World Health Organization, $2^{\text {nd }}$ edition.

[6] Shargie EB, Lindtjørn B (2007). Determinants of treatment adherence among smear-positive pulmonary tuberculosis patients. Journal pmed, 4(2), e37.

[7] Chesney MA, Morin M, Sherr L (2000). Adherence to HIV combination therapy. Soc Sci Med, 50, 1599-1605.

[8] Farmer P (1997). Social scientists and the new tuberculosis. Soc Sci Med. 44, 347-358.

[9] Wares DF, Singh S et al (2003). Non-adherence to tuberculosis treatment, Soc Sci Med, 7, 327-335.

[10] Amare D, Markos T, Yohannis H (2009). TB and HIV co infection its impact on quality of life. Soc Sci Med, 8, 212-230.

[11] Munro SA, Lewin SA, Smith H, Engel ME, Fretheim A, et al (2007). Patient adherence to tuberculosis treatment: A systematic review of qualitative research. PLoS Med, 4(7), e238.

[12] Mekdes K, Gunnar A, Jane F (2010). Barriers and facilitators of adherence to TB treatment in patients on concomitant TB and HIV treatment PLoS Med, 1471-2458.

[13] Mkopi A, Range N, Lwilla F, Egwaga S, Schulze A, et al (2012). Adherence to Tuberculosis Therapy among Patients Receiving Home-Based Directly Observed Treatment: Evidence from the United Republic of Tanzania. PLoS ONE, 7(12), e51828.

[14] Nackers F, Huerga H, Espie' E, Aloo AO, Bastard M, et al (2012). Adherence to Self-Administered Tuberculosis Treatment in a High HIV-Prevalence Setting: A Cross-Sectional Survey in Homa Bay, Kenya. PLoS ONE, 7(3), e32140.

[15] Estifanos Biru, Bernt Lindtjorn (2007). Determinants of treatment adherence among smear-positive pulmonary TB patients in South Ethiopia, 122-130.

[16] Wondimeneh Y, Muluye D, Belyhun Y (2012). Prevalence of PTB and immunological profile of HIV-co infected patient in North west Ethiopia, 456-460.

[17] Monica G, Paul K, Freddy E (2009). Non-adherence to anti-TB drugs among TB/HIV co-infected patients in Mbarara Hospital Uganda. African Health Sciences, 9 (1), 326-371.

[18] Adams SA, Soumeraj BS, Jonathan L, Doss-Degan D (1999). Evidence of self report bias in assessing adherence to guidelines. International Journal for Quality in Health Care, 187-192.

[19] Kebede A and Wube K (2012). Medication adherence and its determinants among patients on concomitant tuberculosis and anti retroviral therapy. North American journal of medical science, 4(2), 60-69.

[20] Jaiswal A, Singh V, Ogden J.A et al (2003). Adherence to tuberculosis treatment: lessons from the urban setting of Delhi, India. Tropical medicine and international health, 8(7), 625-633. 